CORRECTION

\title{
Correction: Effects of neurodevelopmental risk factors on brainstem maturation in premature infants
}

L. Borenstein-Levin, R. Taha, A. Riskin, H. Hafner, A. Cohen-Vaizer, A. Gordin, Y. Littner, G. Dinur, O. Hochwald and A. Kugelman

(c) The Author(s), under exclusive licence to the International Pediatric Research Foundation, Inc 2022

Pediatric Research (2022) 92:335; https://doi.org/10.1038/s41390-022-01960-w

Correction to: Pediatric Research https://doi.org/10.1038/s41390021-01849-0, published online 17 November 2021
In the original version of the article, the names were inserted in the wrong order of the first names and surnames. The original article has been corrected. 